\title{
ЛИТЕРАТУРОВЕДЕНИЕ
}

\author{
Научная статья \\ УДК 821.512 .31 \\ doi: $10.18101 / 2305-459 X-2021-1-25-32$
}

\section{ВОПРОСЫ МЕТОДОЛОГИИ И ТЕРМИНОЛОГИИ ПРИ ИЗУЧЕНИИ МИФОПОЭТИКИ БУРЯТСКОЙ ЛИТЕРАТУРЫ}

\author{
(C) Булгутова Ирина Владимировна \\ доктор филологических наук, доцент, \\ Бурятский государственный университет имени Доржи Банзарова \\ Россия, 670000, г. Улан-Удэ, ул. Смолина, 24а \\ irabulgutova@mail.ru
}

\begin{abstract}
Аннотация. В статье с привлечением культурологического и языкового материала обосновывается тезис о сохранности архаических пластов бурятской мифологии, выявляется важная роль мифологии в оформлении коллективного духовного опыта. Ставится проблема дальнейшего уточнения собственно литературоведческих аспектов анализа мифа, прослеживаются терминологические поиски в бурятском литературоведении последних десятилетий. Материал бурятской литературы позволяет поставить вопрос о роли родного языка писателей в выражении и создании мифопоэтической модели мира, о специфике проявления мифологизма в творчестве писателей, пишущих на родном бурятском языке, и творчестве писателей-билингвов, пишущих на русском языке. Намечается сфера употребления в бурятском литературоведении понятий: «мифосознание», «мифомышление», «мифологизирование». Определяются перспективы изучения мифопоэтики бурятской литературы с учетом особенностей знаковой системы национального языка.
\end{abstract}

Ключевые слова: мифопоэтика; мифологизм; мифологизация; архетип; мифосознание; мифомышление; мифологизирование; мифотворчество; символика; символизация.

\section{Для цитирования}

Булгутова И. В. Вопросы методологии и терминологии при изучении мифопоэтики бурятской литературы // Вестник Бурятского государственного университета. Язык. Литература. Культура. 2021. Вып. 1. С. 25-32.

Мифологическая система бурят нашла свое воплощение в различных видах искусства. Так, в живописи и скульптуре наглядно прослеживается архетипическая образность традиционной культуры. Когда же речь идет о выявлении мифологизма в словесном искусстве и прежде всего в устном народном творчестве, возникают определенные сложности, связанные с разграничением некоторых понятий и представлений. По мнению исследователя, «в духовной жизни народов Сибири прочно живут древние представления их пращуров об окружающем мире, о единстве и кровном родстве человека и природы» [1, с. 28].

Материал мифологии сибирских народов как одной из архаических ее моделей освоен в достаточной степени в работах фольклористов, он также привлека- 
ется в литературоведческих работах, исследовавших взаимодействие фольклора и литературы, тем более исследование взаимосвязи мифологии и литературы многоаспектно и связано с представлениями о разностадиальности истории человеческой культуры и с пониманием особых структур человеческого сознания.

«Но сколь ни велики различия между мифами разных стадий существования человечества, мифология как трансисторический феномен обладает неким комплексом свойств, которые неустранимы и общеобязательны во все времена. В основу определения мифа как надэпохального явления, на наш взгляд, правомерно положить два утверждения: 1) миф - это прежде всего высказывание о предмете общезначимом. Объект мифа - нечто коренное и важное, касающееся миро- и жизнеустройства, либо глубоко значимое для данного социума. Миф имеет прямое отношение к фундаментальным началам космического и земного бытия. И именно поэтому он обретает энергию воздействия на общественное сознание, становится его существенной гранью; 2) миф - это такое общезначимое высказывание, которое требует к себе полного, безоговорочного, нерефлективного доверия и такое доверие вызывает или всеобщее, или по меньшей мере значительной части социума. Освоение и переживание мифа - это овладение некой аксиоматикой, самоочевидной и непререкаемой. Миф, говоря иначе, апеллирует к его некритическому восприятию» [10, с. 13]

В литературоведении XX-XXI веков складывается множество различных подходов к пониманию и толкованию мифа в литературе, что отражается и в терминологических поисках, в русле исследований по мифопоэтике находятся понятия мифологем как мифологических образов, мотивов и сюжетов, архетипов как образов, отражающих структуры коллективного бессознательного, символов как знаков, образующих мифологический код национальной культуры и т. д.

«Развитие подобных разысканий в особенности обнажило ключевую для всей М. (мифопоэтики) проблематику соотношения в авторской мифологии сознательного и бессознательного, творческого и репродуктивного, сконструированного и органического, индивидуального и архетипического» [8, с. 124].

Исследование мифологии в связи с литературой, изучение реализации мифосознания в художественных текстах особенно активно ведутся в новейшую эпоху. Говоря о мифологизме в творчестве латиноамериканских и афро-азиатских писателей XX века, Е. М. Мелетинский отмечает, что для них «мифологические традиции еще являются живой подпочвой национального сознания и даже многократное повторение тех же мифологических мотивов символизирует в первую очередь стойкость национальных традиций, национальной жизненной модели. И у них мифологизм влечет выход за чисто социальные рамки, но социальноисторический план продолжает жить рядом и в особых отношениях «дополнительности» с мифологическим» [6, с. 298].

В литературе сибирских народов также отражается живое бытование в глубинах народной жизни вплоть до новейшего времени мифологического сознания, которое продолжает определять поэтику национального искусства на различных его уровнях. На наш взгляд, говоря о бурятской культуре, сохранившей архаические пласты мифологии в живом бытовании, можно сформулировать тезис об устойчивой связи мифа с коллективным сознанием. Эта связь определяется, с 
И. В. Булгутова. Вопросы методологии и терминологии при изучении мифопоэтики бурятской литературы

одной стороны, активным функционированием архетипов, укорененных в бессознательном, с другой, формированием творческой интенции в контексте традиционных верований. Так, процесс поэтического вдохновения мыслится аналогичным и тождественным тому, что в шаманизме называется «онгоёо оруулха», «онгондоо орохо» - буквально «впускать в себя духов», «входить в дух» или же «говорить... безмолвными устами» предков [7, с. 8].

Представление о наличии крепкой незримой связи с ушедшими поколениями задано самой традицией. В сознании бурят сформировано представление об исключительной важности фактора наследственности, что прослеживается как в представлениях об $y \partial x a-$ генетической предопределенности способностей шамана, так и в обычаях и предписаниях, по которым каждый бурят должен знать семь поколений своего рода. Как известно, «чтобы стать шаманом, человек должен обладать прежде всего наследственностью - удха, т. е. иметь предкашамана» [2, с. 66].

Специфика родового, генетического мышления находит свое отражение в языке, в котором для обозначения родства по материнской линии существует слово «нагаса», для обозначения внуков от сына — «ама» и от дочери — «зээ». Пословица «Уг зээдэ мээхэй» — «Наследственность (родовое начало) ласкова (более склонна передаваться) к детям от дочери» свидетельствует о важности представлений о кровном родстве. Ощущение незыблемой связи с предками одно из базовых представлений в традиции бурят, что не могло не отразиться в художественном творчестве, в котором поэт сродни медиуму — «слышу я голоса неувиденных предков моих» [7, с. 54].

Процесс творчества, таким образом, представляет собой процесс индивидуального прорыва личности к общему духовному деперсонализированному опыту, имеющему объективный характер. В устном народном творчестве бурят абсолютизация ценности коллективного мировоззрения воплотилась в традиции эпического сказывания с ее представлением о сакральности устного звучащего слова. Миф как продукт коллективного опыта предстает в процессе мифологизации истории, что прослеживается в фольклорных произведениях. В частности, во многих исторических песнях элементом композиционной структуры является монолог легендарной или героической личности, чей голос выражает общие устремления и общую ценностную картину мира. Мифологизация истории в традиции связана с активным бытованием устного слова предания, в процессе передачи которого большое значение имеет установление прежде всего эмоциональных связей на конкретно-чувственном уровне.

На протяжении длительного времени одной из значимых проблем в научном осмыслении роли мифа в национальной культуре является определение и разграничение субъектно-объектных отношений. В современных литературоведческих работах активно употребляются в связи с изучением мифопоэтики такие термины, как «мифологемы», «архетипы», «символы», «мифологический сюжет», «мифотворчество», «автобиографический миф», «персональный миф» и т. д. Важной проблемой становится выявление и разграничение сознательного обращения автора к мифологии и бессознательного проявления мифа на глубинных 
уровнях произведения, причём именно то, что проявляется бессознательно, в наибольшей степени обладает художественно-эстетическим потенциалом.

Существует также проблема разграничения самой мифологии от словесного искусства, как отличить миф от поэтической образности? В «Диалектике мифа» А. Ф. Лосева выделен параграф под названием «Миф не есть поэтическое произведение», в котором ученый, обосновывая принципиальную необходимость четких критериев разграничения мифического и поэтического образа, указывает вначале на черты сходства, затем обосновывает их различие. «Поэтическая действительность есть созерцаемая действительность, мифическая же действительность есть реальная, вещественная и телесная, даже чувственная, несмотря ни на какие ее особенности и даже отрешенные качества. Это значит, что тип мифической отрешенности совершенно иной, чем тип поэтической отрешенности. Поэтическая отрешенность есть отрешенность факта или, точнее говоря, отрешенность от факта. Мифическая же отрешенность есть отрешенность от смысла, от идеи повседневной, обыденной жизни» [4, с. 65]. По утверждению ученого, поэзия возможна без мифологии, как и мифология без поэзии. Универсальность мифа делает его феноменом сознания.

В бурятском литературоведении в работах последних десятилетий при обращении к мифу стали употребляться для обозначения контекста авторского творчества такие термины, как «мифо-фольклорный» или «фольклорномифологический», подтверждающие тезис о том, что традиционная культура бурят пронизана мифологизмом. Так, исследователь отмечает, что «обращение литератур Сибири и Севера к национальным мифо-фольклорным истокам является постоянно действующей величиной, обусловленной неразрывностью связей в данном ареале между художественной литературой и устным народным творчеством» [5, с. 11]. По нашему мнению, в исследовании бурятской литературы вполне правомерно использование понятий «мифосознание», «мифомышление», «мифологизирование», терминологическое их употребление, безусловно, имеет конвенциональный характер.

Употребление слова «мифосознание» как термина обосновано необходимостью соотнести уровни сознательного/бессознательного в художественном творчестве, когда нужно найти коррелят коллективному бессознательному. «Миф это первый уровень объяснения, отражения и понимания действительности. Это первая (мифологическая) модель мира, в которой зарождались и концентрировались архетипы - коллективное бессознательное: фантазии, символы, сновидения, идеи, мотивы и т. д., т. е. первые изначальные прообразы внешнего мира» $[9$, c. 8].

Архетип - сфера проявления коллективного бессознательного, мифологема - сфера проявления коллективного сознания, сформированного в определенной традиции. По нашему мнению, мифосознание определяемо как составная часть ноосферы, пласт, пограничный бессознательному. «Мифомышление» как термин целесообразно употреблять для обозначения индивидуальных поисков автора, являющегося носителем мифа национальной культуры как ее текста. «Мифологизирование» же предполагает определенную степень интеллектуальных усилий автора, наличие дистанции, выявить которую можно в художествен- 
И. В. Булгутова. Вопросы методологии и терминологии при изучении мифопоэтики бурятской литературы

ной организации произведения. Между наивной верой в чудесное и сознательным обращением к традиции поле подвижного взаимодействия. Выявление четких маркеров возможно только на основе и вслед за интуитивным освоением ряда художественных явлений.

Материал бурятской литературы позволяет поставить вопросы функционирования языка в различных аспектах, в том числе дает возможность для осмысления «пограничных» процессов в художественном сознании, на стыке двух языков. Реализацию мифа можно проследить как в произведениях, написанных на бурятском языке, так и в произведениях, написанных на русском языке авторамибилингвами. У последних родной язык с присущими ему структурами, связанными с мифосознанием, не стал языком творчества, а оказался в особом положении: «...а рядом, как память о древних монголах, / как их осуждение блудного сына, / сидит беркутенок в моем подъязычье» [7, с. 79].

В какой степени это «подъязычье» может определять реализацию мифологем на бессознательном уровне, включая момент непроизвольной веры в словесное кодирование? В структуре творческой личности, личности художника доминирует сфера бессознательного - такое мнение устоялось в психологии творчества. В моноязычном сознании не возникает противоречие при оформлении своего конкретно-чувственного восприятия, какого рода утраты/обретения происходят на пограничье различных языковых картин мира. По нашему мнению, понятия «мифосознание» и «мифомышление» в большей степени употребимы по отношению к авторам, писавшим на родном языке, так как здесь больше вероятность некритичного освоения мира. «Мифологизирование» в качестве термина, на наш взгляд, обозначает степень сознательного обращения к традиции, что прослеживается в творчестве русскоязычных авторов-бурят. Так, представление о сакральной силе слова живет в сознании носителей бурятского языка, определяя и систему запретов. В частности, возможно, этим и определяется обращение бурятских писателей к «шаманскому сюжету» только в произведениях на русском языке. В модели «мысль - слово - действие» слово имеет ключевую роль в древних жанрах заклинания, заговора, призывания, благопожелания и т. д., что определяется, по всей видимости, связью с ритуальной основой. Миф как древнейшая структура отражает связь уровней бессознательного, конкретночувственного с сознательным, интеллектуальным началом, что сродни «проговариванию» подсознательных потоков. Компонент непроизвольной веры в слова основан на автоматизме восприятия целых блоков информации. Энергоинформационная природа слова усваивается на родном языке «с молоком матери». Конкретно-чувственное восприятие человека, его «язык тела» или же «телесный язык» (с лимитированным набором элементов) оформляется на родном языке. Усвоение последующих языков активизирует в большей степени понятийный аппарат, поэтому «первородный» мифологизм связан со сферой родного языка. Роль языка в процессе художественного творчества в связи с реализацией мифологии как универсального общечеловеческого достояния трудно переоценить.

Большое значение в выражении традиционного духовного опыта народа в авторском творчестве приобретают символы как специфические знаки, выводящие 
за грань чувственно воспринимаемого мира и оформляющиеся в лоне национальной культуры.

Знаковая природа символа, имеющего прежде всего предметное значение в материальном мире, рассчитана на «считывание» дальнейшего ряда значений, уводящих в сферу трансцендентального. Прорыв в сферы, не доступные для конкретно-чувственного восприятия человека, для творческой личности - путь самоуглубления и интуитивного постижения закономерностей всеобщего устройства вселенной и человека и есть тропа мифа, освещаемая символом. По мнению А. Ф. Лосева, «миф никогда не есть только схема или только аллегория, но всегда прежде всего символ, и, уже будучи символом, он может содержать в себе схематические, аллегорические и усложненно-символические слои» [4, с. 62].

В бурятском литературоведении чрезвычайно актуально исследование связи мифологии и символики с учетом важной роли символизации в традициях, обрядах и обычаях бурят. Таков, например, образный ряд снов, символика которых толкуется мифологически в контексте как шаманских верований, так и буддийской религиозной мифологии. Знаковый характер в традиционных обрядах и обычаях бурят приобретают все вещи, явления природного и космического плана, а также и действия человека. Следует также отметить важность самого канала конкретно-чувственного восприятия - «провода», который моделируется языком. На сегодняшний день в литературоведении проработаны в определенной мере уровни цветовой и звуковой символики. Анализ ольфакторных образов также может выводить на уровень символических обобщений. Материал бурятской культуры позволяет говорить о символизации на основе сплетения «проводов» слуха, обоняния, осязания, вкуса, зрения с акцентированием «незримых» уровней. В любом случае важно определить закономерности в структурировании реальности и того, что за ней, на основе языкового «кодирования». «Буквализм» восприятия, таким образом, очень важен, так как в сфере предметной определяема закономерность связей и логика сцеплений, которая затем проецируется на уровни за пределами конкретно-чувственного восприятия. Символ «не только связан с нерасчленимым мировым целым, но он способ выражения невыразимой другими словами целостности мира - в этом смысл и внесмысловая активность его неисчерпаемой многозначности» [8, с. 226].

Употребление в связи с толкованием символов бурятской культуры понятия «код» в бурятском литературоведении обосновано в работах Л. С. Дампиловой. Так, исследователь отмечает, что «при определении традиционных культурных кодов мифологемы и архетипы рассматриваются как основополагающие средства» $[3$, с. 4$]$.

Для обозначения индивидуально-авторского поиска по созданию образного ряда, следуя логике мифа, как определение возможности новых художественных открытий вполне применим термин «мифотворчество». Индивидуальноавторские искания могут выявляться и в метафоризации - процессе выявления сущности вещей и явлений мира через установление скрытых связей между ними.

В этнографических работах, дающих обобщающее представление о народной жизни разных эпох, формируется представление о мифологии как историческом явлении, характерном для глубокой древности, как типе мышления первобытно- 
И. В. Булгутова. Вопросы методологии и терминологии при изучении мифопоэтики бурятской литературы

го человека. С другой стороны, с точки зрения психологии стал возможным подход объяснения мифа как феномена человеческого сознания, исходя из его моделирующей функции.

При всем различии подходов к изучению мифа в литературе очевидна актуальность исследований мифопоэтики, раскрывающих закономерности как индивидуального творчества, так и литературного процесса в целом.

Литература

1. Балданов С. Ж. Народно-поэтические истоки национальных литератур Сибири (Бурятии, Тувы, Якутии): автореферат диссертации на соискание ученой степени доктора филологических наук. Улан-Удэ: Изд-во БГПИ, 1995. 30 с. Текст: непосредственный.

2. Галданова Г. Р. Доламаистские верования бурят. Новосибирск: Наука, 1987. 114 с. Текст: непосредственный.

3. Дампилова Л. С. Духовно-культурные коды в поэзии монгольских народов. Иркутск: Оттиск, 2016. 244 с. Текст: непосредственный.

4. Лосев А. Ф. Философия. Мифология. Культура. Москва: Издательство политической литературы, 1991. 526 с. Текст: непосредственный.

5. Малзурова С. Д.-Н. Мифо-фольклорные истоки прозы народов Сибири и Севера 60-80-х гг. ХХ века: автореферат на соискание ученой степени кандидата филологических наук. Улан-Удэ: Изд-во Бурят. гос. ун-та, 2015. 26 с. Текст: непосредственный.

6. Мелетинский Е. М. Поэтика мифа. Москва: Восточная литература РАН, 2000. 408 с. Текст: непосредственный.

7. Нимбуев Н. Ш. Стреноженные молнии. Стихи. Переводы. Проза. Москва: Галерея «Ханхалаев», 2003. 308 с. Текст: непосредственный.

8. Поэтика: словарь актуальных терминов и понятий. Москва: Издательство Кулагиной, Intrada, 2008. 358 с. Текст: непосредственный.

9. Уланов Э. А. Фольклор в контексте бурятского словесного творчества. УланУдэ: Изд-во Бурят. гос. ун-та, 2001. 208 с. Текст: непосредственный.

10. Хализев В. Е. Мифология XIX-XX веков и литература // Вестник МГУ. Серия Филология. 2002. № 3. С. 7-20. Текст: непосредственный.

Статья поступила в редакиию 29.01.2021; одобрена после рецензирования 24.02.2021; принята к публикачии 05.03.2021.

\section{METHODOLOGICAL AND TERMINOLOGICAL PROBLEMS OF STUDYING THE MYTHOPOETICS OF BURYAT LITERATURE}

Irina V. Bulgutova

Cand. Sci. (Phil.), A/Prof.,

Institute of Philology and Mass Communications

Dorzhi Banzarov Buryat State University

24a Smolina St., Ulan-Ude 670000, Russia

irabulgutova@mail.ru

Abstract. In the article using cultural and linguistic material, we present an argument for preserving the archaic layers of Buryat mythology, reveal the significance of mythology in the development of collective spiritual experience. The further clarification of the literary aspects of myth analysis is problematized. We have traced terminological searches in 
the Buryat literary criticism of the last decades. The material of the Buryat literature makes it possible to raise the question of the role of writers' native language in the expression and creation of the mythopoetic model of the world, the specificity of mythology manifestation in the work of authors, writing in the native Buryat language, and the work of bilingual authors writing in Russian. We have outlined the scope of use of the concepts "mythic consciousness", "mythic thinking", "mythologizing" in Buryat literary criticism. The article defines the prospects for studying the mythological poetics of Buryat literature with consideration of the specificity of the national language semiotic system.

Keywords: mythopoetics; mythologism; mythologization; archetype; mythic consciousness; mythic thinking; mythologizing; myth-making; symbolism; symbolization.

\section{For citation}

Bulgutova I. V. Methodological and Terminological Problems of Studying the Mythopoetics of Buryat Literature. Language. Literature. Culture. 2021; 1: 25-32 (In Russ.).

The article was submitted 27.01.2021; approved after reviewing 18.02.2021; accepted for publication 05.03.2021. 